\title{
Corrections
}

\section{Correction: Slaker et al., Removal of Perineuronal Nets in the Medial Prefrontal Cortex Impairs the Acquisition and Reconsolidation of a Cocaine-Induced Conditioned Place Preference Memory}

In the article "Removal of Perineuronal Nets in the Medial Prefrontal Cortex Impairs the Acquisition and Reconsolidation of a Cocaine-Induced Conditioned Place Preference Memory" by Megan Slaker, Lynn Churchill, Ryan P. Todd, Jordan M. Blacktop, Damian G. Zuloaga, Jacob Raber, Rebecca A. Darling, Travis E. Brown, and Barbara A. Sorg, which appeared on pages 4190-4202 of the March 11, 2015 issue, there were errors in the $y$-axis scales of Figure 7, $C$ and $E$. The $y$-axis scale on Figure $7 C$ should be the $y$-axis scale on Figure $7 E$, and the $y$-axis scale on Figure $7 E$ should be the $y$-axis scale on Figure $7 C$. This error does not affect any of the conclusions or interpretations in our paper. The correct Figure 7 is shown below.
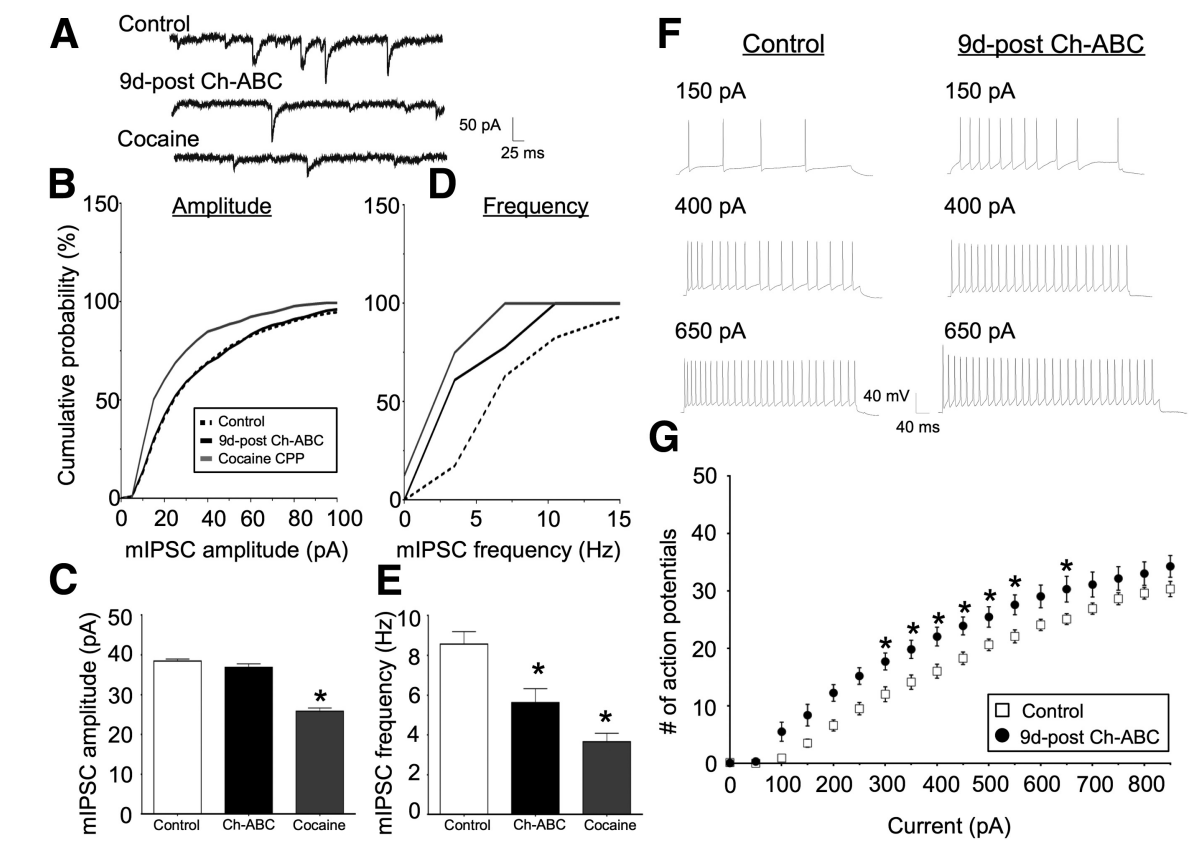

Figure 7.

DOI:10.1523/JNEUROSCI.1503-15.2015

\section{Correction: Fields et al., HIV Tat Alters Neuronal Autophagy by Modulating Autophagosome Fusion to the Lysosome: Implications for HIV-Associated Neurocognitive Disorders}

In the article "HIV Tat Alters Neuronal Autophagy by Modulating Autophagosome Fusion to the Lysosome: Implications for HIVAssociated Neurocognitive Disorders” by Jerel Fields, Wilmar Dumaop, Simona Elueteri, Sofia Campos, Elisabeth Serger, Margarita Trejo, Kori Kosberg, Anthony Adame, Brian Spencer, Edward Rockenstein, Johnny J. He, and Eliezer Masliah, which appeared on pages 1921-1938 of the February 4, 2015 issue, the third author's last name was incorrectly listed. The corrected author line is: Jerel Fields, Wilmar Dumaop, Simona Eleuteri, Sofia Campos, Elisabeth Serger, Margarita Trejo, Kori Kosberg, Anthony Adame, Brian Spencer, Edward Rockenstein, Johnny J. He, and Eliezer Masliah, which has been corrected on the online PDF version. 